\title{
Research on Dissemination Rule of Public Opinion from SNA Perspective: Taking the Vaccine Safety Event as an Example
}

\author{
Jia Wang ${ }^{1}$, Mengyao Guo ${ }^{1}$, Li Zhang ${ }^{1}$, Lujie Chen ${ }^{1}$, Xiaorong Hou ${ }^{1}$ \\ ${ }^{1}$ College of Medical Informatics, Chongqing Medical University, Chongqing 400016, China \\ Correspondence: Xiaorong Hou, College of Medical Informatics, Chongqing Medical University, Chongqing 400016, \\ China.
}

Received: February 16, 2017

Accepted: March 7, 2017

Online Published: March 15, 2017

doi:10.11114/smc.v5i1.2039

URL: https://doi.org/10.11114/smc.v5i1.2039

\begin{abstract}
With the rapid development of social media, the dissemination of health information has attracted more attention from people. To reveal the rule and mode of information diffusion path is the key to effective crisis prevention and control of information. In this paper, the team took the vaccine safety events as an example, selected and analyzed two hottest microblogs from each phase of one event. The team did visual analysis via Zhiwei which was one academic micro data analysis platform, and utilized social network analysis (SNA) to explore the propagating rules of public opinion.
\end{abstract}

Keywords: vaccine event, social network analysis, microblog, public opinion, dissemination

\section{Introduction}

\subsection{Health Information Dissemination}

In the era of information explosion, people pay more attention and prepare for participation on health public opinion, with convenient grasp of the dynamic development of health events. Research and analysis of the dissemination rule of public opinion might control the crisis information effectively (Chengzhi Y, 2011). Just like Facebook, Twitter and Instagram, as one of the most popular social medials in China, Sina microblog provides micro-blogging service in its social networking site where users can edit messages or upload pictures about their daily life or something else happened around them(Xiaohui L., Siqi D. , \& Zhaixing J., 2015). It is easy to become the birthplace of public opinion events.

This paper took Sina microblog as the carrier of information and the recent vaccine safety event with high attention as an example. From the perspective of social network analysis, this paper employed the visual method to analyze the health information dissemination path and explore the diffusion rule and mode of health information from the social media (Rongying Z, \& Jing W, 2011).

\subsection{Review of Vaccine Events}

On March 18, 2016, @澎湃新闻 issued a blog with the title vaccines valued hundreds of millions of Yuan inflow into 18 Province without refrigeration: Possible to bring influence to life, Shandong sends investigation letters widely which immediately attracted great attention from the public. In one month, this event triggered a large-scale attention and repost in Sina microblog and WeChat. The network public opinion fueled the vaccine event rapidly. Our team sorted out the occurrence and development of the vaccine events from four stages: start-formation-down-end. We selected 12 microblogs with high attention around 3 voice points: the government, the media and users of personal authentication, as shown in Table 1. 
Table 1. Comparison of blogs in each phase of the vaccine event

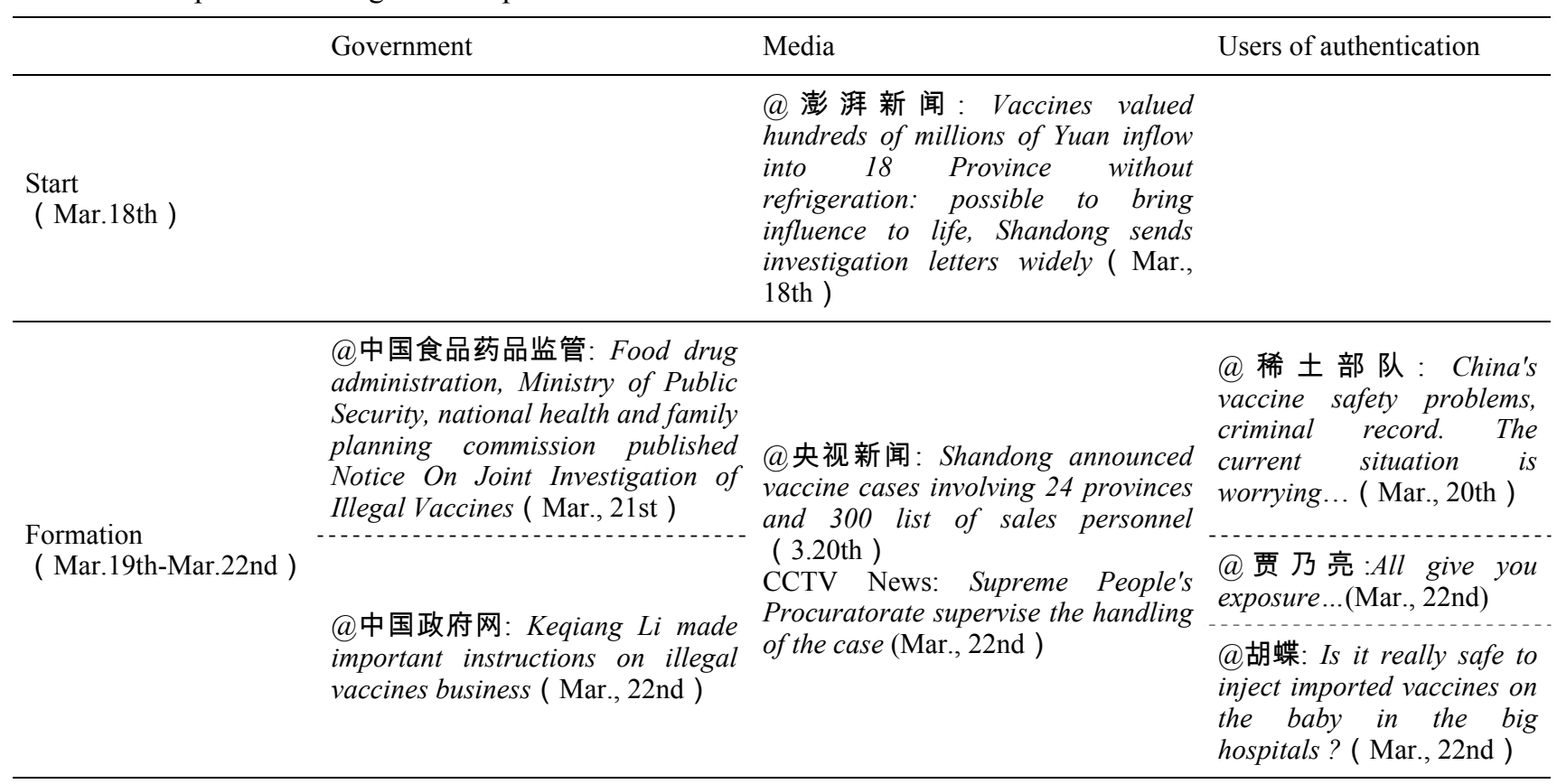

(a)新浪头条: The food and drug administration announced: the vaccine involved are qualified (Mar., 23rd)

(a) 央视新闻: Ministry of Public Security said Shandong vaccine case has been placed on record 69 cases, Down

( Mar.23rd-Apr.12th ) more than 130 suspects were arrested(Mar., 24th)

(a) 央视新闻: Ministry of Public Security, National Health and Family Planning Commission of PRC, the State Food and Drug Administration for the "Shandong vaccine incident held a joint press conference" ( Mar., 24th)

\begin{tabular}{ll}
\hline End & @ 中国政府网: Executive meeting \\
( Apr.13rd) & of the State Council conducted \\
& people involved on trial (Apr. 13rd)
\end{tabular}

Notes: In order to keep the authenticity of the research, we retained the name of micro-blog in original language.

\section{Method}

\subsection{Social Network Analysis}

Smooth flow of social media information, depends largely on the social media relationships between users. Users' relations constitute a complex network structure. Therefore, to study the information dissemination of social media, it is needed to establish the physical form of communication channels firstly. This requires analysis by means of the social network. SNA, a set of norms and methods for analyzing the structure and attributes of social relations, mainly analyzes the structure and attributes of different social units, and reveals research hot spots essentially and finely by establishing visualization and measurement directly on the social network (Song G., 2011).

\subsection{ZhiWei Dissemination Analysis—www.weiboreach.com}

Combining the principle of social network analysis, the team collected the institution of attention, repost and comment by analyzing the original microblog text. By counting characteristics of the information repost rate with time, the paper detected the effect of the information dissemination, analyzed the path and process of information repost, and displayed the dissemination path, key words, dissemination time and repost range visually. 


\section{Data Analysis of Dissemination}

\subsection{Reposting Time Trend}

Table 2. Reposting time trend in each stage

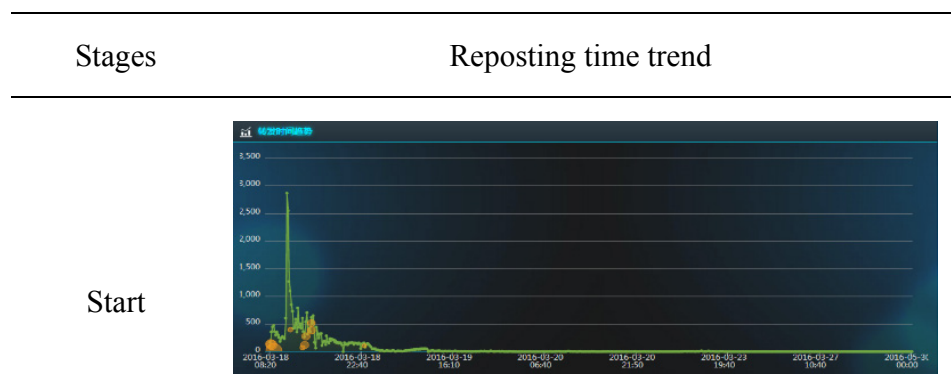

Time trend of @澎湃新闻
One Sinamicroblog published by @澎湃新闻 at

8:22 on March $18^{\text {th }}$, drew attention of various

medias and civilians. Within 3 hours, the repost

amount in unit time reached achieved 2800 and

reached the peak during 23:00-24:00.

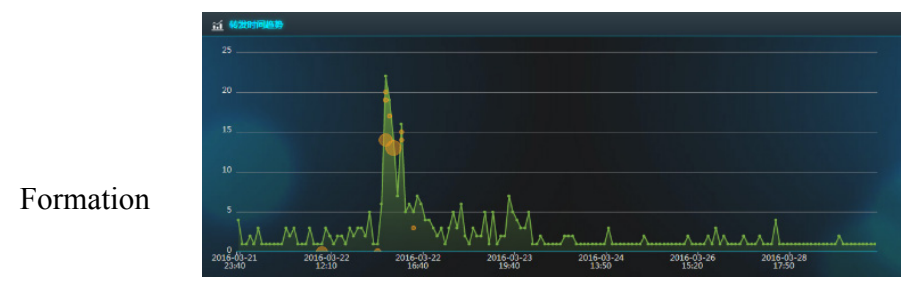

Time trend of @中国食品药品监管
At 23:40 on March $21^{\text {rt }}$, the government responded actively. @中国食品药品监管 published a microblog. Its repost amount reached a peak during 13:00-15:00 on March $22^{\text {nd }}$, but just with a maximum repost amount in unit time less than 25 .

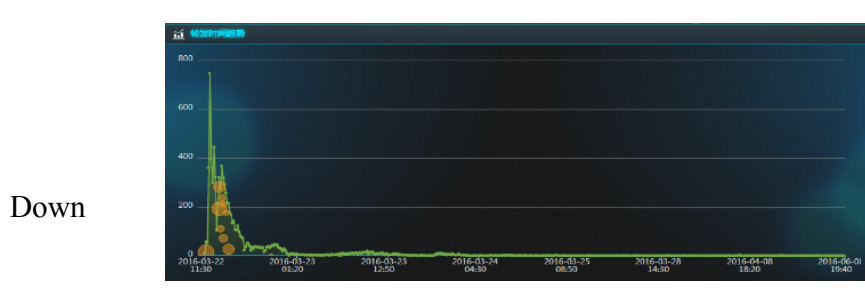

Time trend of @ 胡蝶
At 11:30 on March 22 $2^{\text {nd }}$, @胡蝶 published a relevant microblog with pictures of the news of illegal vaccine flowing to 24 provinces and regions. This microblog was reposted rapidly and reached its climax during 13:00-14: 00, its maximum repost amount in unit time reached about 700 .

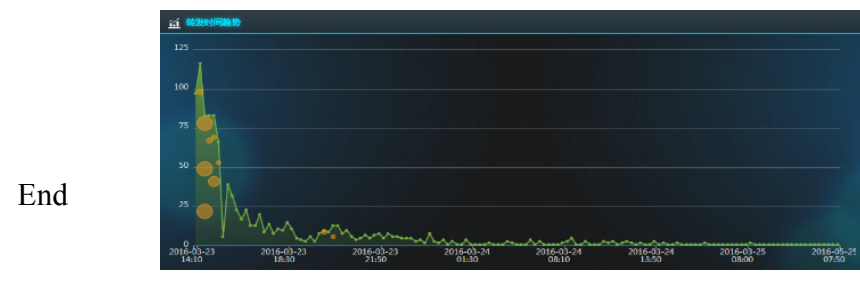

Time trend of @头条新闻
At 14:10 on March 23 ${ }^{\text {rd }}$, @ 新浪头条 published a

microblog. During 14:00-15:00, its repost amount

reached the peak, with a maximum repost amount

in unit time about 125. People reposted the blog

rapidly and participated in discussion actively.

In the end (April 13rd), @Chinese Government published a microblog entitled executive meeting of the State Council conducted people involved on trial. So far, the vaccine event came to the end. Although people were paying attention to the vaccine events and continuing to repost this information, its maximum repost amount merely reached 125 . Table 3 showed the time lasting from information release to peak, and the repost amount in unit time. 
Table 3. Comparison of time and repost amount in the vaccine event

\begin{tabular}{cccc}
\hline Stage & Publisher & $\begin{array}{c}\text { time lasting } \\
\text { from release to peak }\end{array}$ & repost amount in unit time \\
\hline Start & Media & 3 hours & 2800 times \\
Formation & Government & 15 hours & 25 times \\
& Users of authentication & 1.5 hours & 700 times \\
Down & Media & 1 hour & 125 times \\
End & Government & 0.5 hour & 125 times \\
\hline
\end{tabular}

\subsection{Keywords}

The vaccine event lasted for a long duration and caused wide impact. During the whole process from the start to the end, users of personal authentication, government as well as the media conducted hot spot transmission continuously with the mode of original - Repost - Comment, and a large number of keywords appeared (Group S., 2011).Repetition of these key words which represented communicators' attitude concerning to this event on each phase promoted the continuous development of public opinion.

Table 4. High frequency words in each phase of the vaccine event

\begin{tabular}{|c|c|c|c|c|c|c|c|c|c|c|c|}
\hline Stage & type & word & $\mathrm{F}$ & word & $\mathrm{F}$ & word & $\mathrm{F}$ & word & $\mathrm{F}$ & word & $\mathrm{F}$ \\
\hline \multirow{2}{*}{ Start } & $\begin{array}{c}\text { optimistic } \\
\text { word }\end{array}$ & accuracy & 97 & prestige & 55 & autonomy & 48 & try & 48 & publicity & 44 \\
\hline & $\begin{array}{c}\text { pessimistic } \\
\text { word }\end{array}$ & anger & 236 & disease & 182 & kill & 62 & illegal & 58 & fuck & 58 \\
\hline \multirow{2}{*}{$\begin{array}{l}\text { Form- } \\
\text { ation }\end{array}$} & $\begin{array}{l}\text { optimistic } \\
\text { word }\end{array}$ & benefit & 1212 & authority & 632 & thorough & 619 & harvest & 618 & timely & 79 \\
\hline & $\begin{array}{c}\text { Pessimistic } \\
\text { word }\end{array}$ & crisis & 640 & hurt & 639 & against & 636 & bitter & 577 & greed & 193 \\
\hline \multirow{2}{*}{ Down } & $\begin{array}{c}\text { optimistic } \\
\text { word }\end{array}$ & qualified & 326 & important & 60 & hope & 29 & thorough & 16 & $\begin{array}{l}\text { Ensure } \\
\text { /praise }\end{array}$ & 15 \\
\hline & $\begin{array}{c}\text { pessimistic } \\
\text { word }\end{array}$ & anger & 177 & illegal & 35 & fuck & 34 & disease & 25 & mistake & 24 \\
\hline \multirow{2}{*}{ End } & $\begin{array}{l}\text { optimistic } \\
\text { word }\end{array}$ & service & 41 & praise & 11 & first & 9 & good deed & 1 & hope & 1 \\
\hline & $\begin{array}{c}\text { pessimistic } \\
\text { word }\end{array}$ & collapse & 4 & revert & 1 & maggots & 1 & always & 1 & malfeasance & 1 \\
\hline
\end{tabular}

\section{Notes: F infers Frequency.}

\subsection{Bursting Point and Dissemination Path}

\subsubsection{Bursting Point}

The bursting point which affects the depth and width of the spread of public opinion is an indispensable part in the spread of public opinion. In the start stage of the vaccine event, the information released by @澎湃新闻 became the icon bursting point which stimulated 15990 times of secondary repost. Then four bursting points brought out by@姚晨， (a) 陈坤 and other V users evoked 651 times of secondary repost, as shown in Table 5.In the formation and down stage, the media's secondary repost amount was still high. Users of personal authentication in this stage functioned as the key bursting point, causing a large number of secondary reposting, as shown in Table 6. 
Table 5. Statistics of the secondary repost amount in start stage

\begin{tabular}{llll}
\hline User type & @ 澎湃新闻 & V users & users of personal authentication \\
\hline secondary repost amount & 15990 times & 5248 times & 651 times \\
\hline
\end{tabular}

Table 6. Statistics of the secondary repost amount in formation and down stage

\begin{tabular}{|c|c|c|c|}
\hline User type & bursting point & $\begin{array}{l}\text { secondary } \\
\text { amount }\end{array}$ & repost \\
\hline \multirow{3}{*}{ government } & government & 795 & \\
\hline & V users & 124 & \\
\hline & users of personal authentication & 22 & \\
\hline \multirow{3}{*}{ media } & media & 1536 & \\
\hline & V users & 175 & \\
\hline & users of personal authentication & 106 & \\
\hline \multirow{3}{*}{$\begin{array}{l}\text { users of } \\
\text { personal authentication }\end{array}$} & @胡蝶 & 10913 & \\
\hline & V users & 6613 & \\
\hline & users of personal authentication & 2978 & \\
\hline
\end{tabular}

\subsubsection{Dissemination Path}

In order to accurately describe the path of information dissemination and to compare the differences in four stages, this paper respectively selected one microblog of the government, media and the users of personal authentication on the same date, March, $22^{\text {nd }}$. The ZhiWei platform provided each information dissemination path with visual analysis, shown in Table 7. 
Table 7. Dissemination path

\begin{tabular}{lll}
\hline User type & Path graph & Description \\
\hline
\end{tabular}

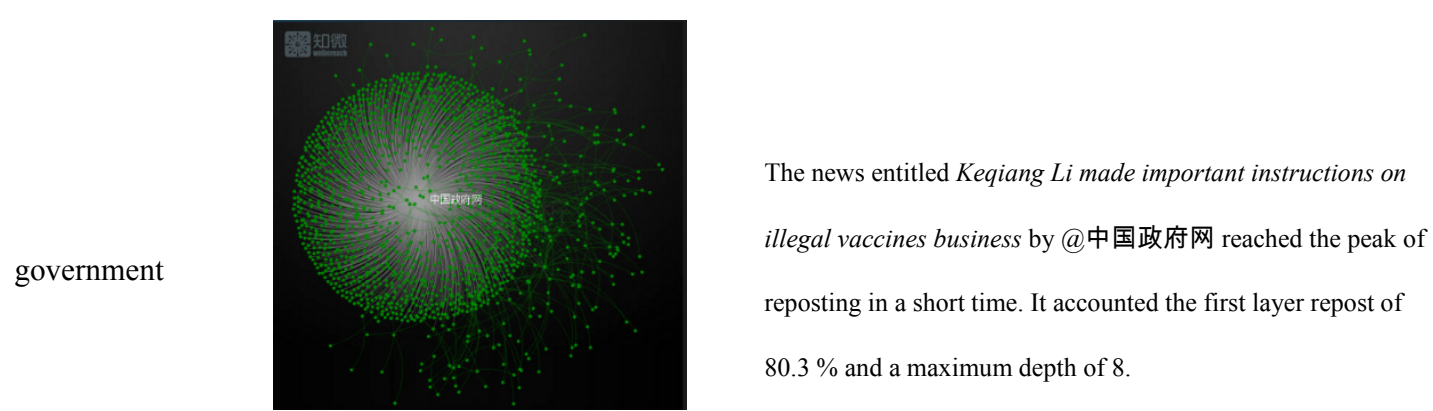

Dissemination path of @中国政府网

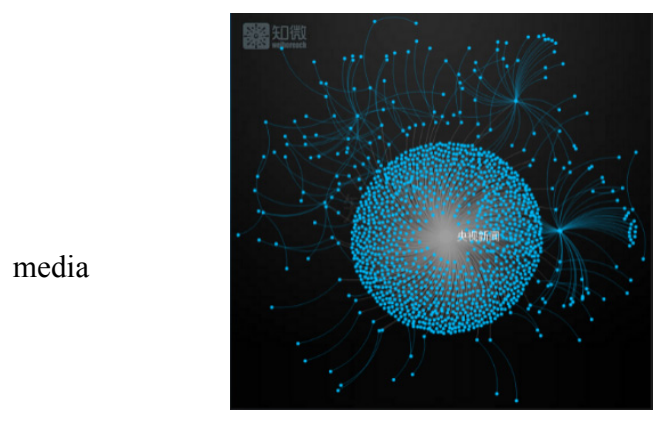
@ 央视新闻 issued the news entitled Supreme people's
procuratorate starts supervising and handling the case of illegal vaccines business, and criminal qualified should be arrested in time. It accounted the first layer repost of $84.8 \%$ and a maximum depth of 6 .

Dissemination path of @ 央视新闻

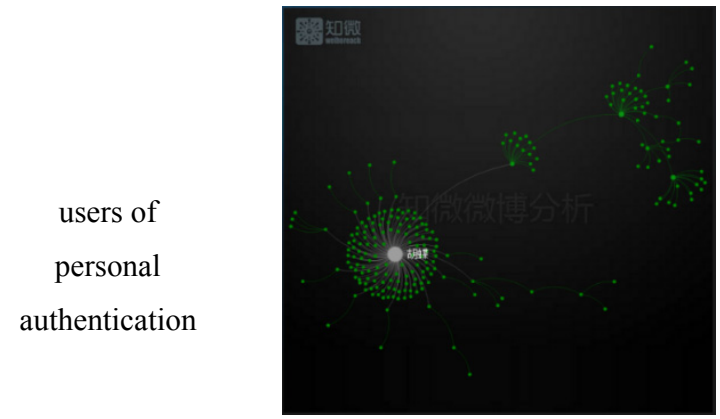
@ 胡蝶 published the original information entitled Is it really
safe to inject imported vaccines on the baby in the big
hospitals? with pictures of the news of illegal vaccine flowing
to 24 provinces and regions. It accounted the first layer repost
of $66.7 \%$ and a maximum depth of 9 .

Dissemination path of @胡蝶

\section{Analysis of Dissemination Rules}

- Media functioned as the chief bursting points and the users of personal authentication sped up the dissemination process.

Media functioning as chief bursting point and $\mathrm{V}$ users functioning as main bursting point extended the width of the dissemination of public opinion and played a crucial role in the process of it (Yang Z, \& Wanyang L, 2012); common users widened the dissemination depth and accelerated the spread of public opinion among common people.

\section{- Publishers and the transmission phase had a direct impact on the dissemination time.}

In different stages, dissemination times of microblogs by the same publisher differed. In the formation-down stage, media's microblogs required a shorter time from the publication period to its peak, and got a lower repost quantity in unit time. In the same stage, the dissemination times of microblogs by different publishers were different. Government's 
microblogs required a longer time from the publication period to its peak, but got a lower repost quantity in unit time (Kuhlman, Kumar, \& Ravi, 2013).

\section{- Communicators were constantly changing with the development of this event.}

During the whole process of this event, the government, the media as well as the users of personal authentication, all played important roles (Savigny, 2002). However, the communicators and their participation degree were different in each phase.

In the start phase, media was the main communicator, and the first exposure by media (@澎看新闻) attracted considerable attention; in the formation phase, the users of personal authentication, media and government were active, the users of personal authentication concerned and participated in the topic, relative government departments investigated and handled the case, and the media kept series reports in time; in the down phase, media returned to be the main communicators by promoting the relevant reports continuously; in the end phase, government was the main communicators, while the users of personal authentication and the media had few comments (Wolfe, 1997).

\section{- Characteristics of high frequency words shifted from being negative to being positive over time.}

With a gradual diffusion of public opinion, both the quantity of positive high-frequency words and that of the negative high frequency words changed according to the trend of being less-more-less as time went on. This indicated that the degree of people's concern to the Shandong vaccine event changed over time (Xiong, Gang, Huang, Chen, \& Ke, 2013). In the start stage, the quantity of the negative high frequency words was significantly larger than that of the positive ones. The inborn negative colors of the poisonous vaccine event would lead to public anxiety, concerns about exposure to social malign events and the hatred towards notorious people. However, in the formation-down-end stage, the quantity of the positive high frequency words was larger than that of the negative ones. This fact indicated that certain influence and positive energy had been brought with the involvement of media and government, and it also reflected people's concern and trust on government's responsibility.

\section{- Microblog repost was the main dissemination path and government showed an enormous influence.}

Microblog repost was the main dissemination path of public opinion. The first level of the media had a high repost proportion and a low depth; the first layer of the government had a high repost proportion and a higher depth, while the first level of the users of personal authentication had a low repost proportion and a high depth. Media and the users of personal authentication had both advantages and disadvantages in the repost proportion and depth. With media's exposure and large V bloggers' repost, public concern and participation in live discussions arose, which would easily lead to a climax of people's repost and comment. Government played a moderate role in the dissemination path (Jalili, 2013). Though the government microblog was set not to be commented, it showed great influence on the development of the whole vaccine events.

Notes: Almost the bloggers mentioned in this article registered with their real names. Hudie(胡蝶), Yaochen(姚晨) and Chenkun(陈坤) are all Chinese stars, having a great influence on Sina microblog.

\section{Acknowledgements}

This paper is supported by the National Social Science Foundation of China (GrantNo.14CTQ022) \& innovation project of college of medical informatics, Chongqing Medical University (GrantNo.2016C002).

\section{References}

Chengzhi, Y. (2011). Analysis on the changing mechanism of mass emergency network public opinion. Journal of Intelligence, 30(12), 6-12. http://dx.chinadoi.cn/10.3969\%2fj.issn.1002-1965.2011.03.026

Group, S. (2011). The Trend of Public Opinion and Patterns of Communication in the Rush of Salt: Based on the Intelligent Analysis of Network Text. Journal of International Communication, 26(3), 385-404.

Jalili, M. (2013). Social power and opinion formation in complex networks. Physica A Statistical Mechanics \& Its Applications, 392(4), 959-966. http://dx.doi.org/10.1016/j.physa.2012.10.013

Kuhlman, C. J., Kumar, V. S. A., \& Ravi, S. S. (2013). Controlling opinion propagation in online networks. Computer Networks the International Journal of Computer \& Telecommunications Networking, 57(10), 2121-2132. https://doi.org/10.1016/j.comnet.2012.11.025

Savigny, H. (2002). Public Opinion, Political Communication and the Internet. Politics, 22(1), 1-8. https://doi.org/10.1111/1467-9256.00152

Song, G. (2011). Exploring Method of Measuring and Visualizing Focuses Based on SNA. Journal of Modern Information, 31(05), 46-54. http://dx.chinadoi.cn/10.3969\%2fj.issn.1008-0821.2011.05.010 
Wolfe, A. W. (1997). Social Network Analysis: Methods and Applications. American Ethnologist, 24(1), 219-220. https://doi.org/10.1525/ae.1997.24.1.219

Xiao, H. L., Si, Q. D., \& Zhai, X. J. (2015). Investigation of College Students' Mental Health Status via Semantic Analysis of Sina Microblog. Wuhan University Journal of Natural Sciences, 20(2), 159-164. http://dx.chinadoi.cn/10.1007\%2fs11859-015-1075-z

Xiong, X. B., Gang, Z., Huang, Y. Z., Chen, H. Y., \& Ke, X. (2013). Dynamic evolution of collective emotions in social networks: a case study of Sina weibo. Science China Information Sciences, 56(7), 1-18. https://doi.org/10.1007/s11432-013-4892-8

Yang, Z., \& Wan, Y. L. (2012). A comparative study of information diffusion in weblogs and microblogs based on social network analysis. Chinese Journal of Library \& Information Science, 12(4), 446-450.

Zhao R, \& Wang J. (2010). Research of International Webometrics in Frontier Domains in Visualized Information. Management and Service Science (MASS), 2010 International Conference on. IEEE, 1-4. http://dx.doi.org/10.1109\%2FICMSS.2010.5578455

\section{Copyrights}

Copyright for this article is retained by the author(s), with first publication rights granted to the journal.

This is an open-access article distributed under the terms and conditions of the Creative Commons Attribution license which permits unrestricted use, distribution, and reproduction in any medium, provided the original work is properly cited. 